\title{
Urinary Schistosomiasis in Children-Still a Concern in Part of the Ghanaian Capital City
}

\author{
Patience B. Tetteh-Quarcoo ${ }^{1 *}$, Simon K. Attah ${ }^{1}$, Eric S. Donkor ${ }^{1}$, Marian Nyako ${ }^{2}$, \\ Andrew A. Minamor ${ }^{3}$, Emmanuel Afutu $^{1,4}$, Edward T. Hervie ${ }^{3}$, Patrick F. Ayeh-Kumi ${ }^{1,5}$ \\ ${ }^{1}$ Department of Microbiology, University of Ghana Medical School, Accra, Ghana \\ ${ }^{2}$ Department of Biochemistry, Cell and Molecular Biology, University of Ghana, Accra, Ghana \\ ${ }^{3}$ Neglected Tropical Disease Program, Disease Control \& Prevention Department, Ghana Health Service, Accra, Ghana \\ ${ }^{4}$ Department of Science Laboratory Technology, Accra Polytechnic, Accra, Ghana \\ ${ }^{5}$ Department of Medical Laboratory Sciences, University of Ghana School of Allied Health Sciences, Accra, Ghana \\ Email: *patborket2002@yahoo.com
}

Received June 15, 2013; revised July 15, 2013; accepted July 23, 2013

Copyright (C) 2013 Patience B. Tetteh-Quarcoo et al. This is an open access article distributed under the Creative Commons Attribution License, which permits unrestricted use, distribution, and reproduction in any medium, provided the original work is properly cited.

\begin{abstract}
Schistosomiasis is a parasitic disease of the tropics which is estimated to affect up to 300 million people worldwide. While it is being successfully controlled in many countries, it remains a major public health problem, especially in developing countries including Ghana. Extensive work on schistosomiasis has been undertaken along the Volta River basin, leaving very little data and information on this infection in the urban and peri-urban areas in Ghana. This study was aimed at determining the urinary schistosomiasis burden among children of school going age within Zenu, a suburb of the capital city. Urine samples were taken from 274 school children within the Zenu community and examined with urine chemistry dipsticks for detection and confirmation of haematuria, followed by microscopy for detection of Schistosoma haematobium ova. Prevalence of urinary schistosomiasis was $30.7 \%$ (95\% CI: $25.2-36.2)$. 44 (52\%) of the positive samples were collected from males whiles $40(48 \%)$ were collected from females, but prevalence of the infection was not significantly associated with gender $\left(\chi^{2}=0.041, \mathrm{DF}=1, \mathrm{P}-\right.$ Value $\left.=0.839\right)$. Among the $S$. haematobium positive children, haematuria was detected by the dipstick in $88.1 \%$ (74/84, 95\% CI: $81.2-95.0)$, but it was not detected in $11.9 \%$ (10/84, 95\% CI: 5.0 - 18.8). Meanwhile, the dipstick detected haematuria in 7.3\% (20/274, 95\% CI: 4.3 - 7.3) of the total population but microscopy could not detect the presence of Schistosoma ova in those children. An association was found between Schistosoma infection and haematuria detected by dipstick $\left(\chi^{2}=84.715\right.$, DF $=1$, P-Value $<$ 0.001 ). It could be noted that urinary schistosomiasis in children is still a concern in parts of the Ghanaian capital city.
\end{abstract}

Keywords: Schistosomiasis; Haematuria; Schistosoma haematobium; Accra

\section{Introduction}

In spite of the fast improving knowledge in the area of urinary schistosomiasis, which cuts across global burden, treatment, and associated morbidity [1-4], there are repeated cases of these parasites in humans, especially children. This causes untold hardship as a result of the associated morbidities and mortalities [5,6]. Proteinuria, dysuria and especially haematuria are among the morbidities. High mortality rate can occur as a result of complications arising from granulomatous inflammation, ulceration, and depletion of the vesical and ureteral walls [7], renal insufficiency and failure [8]. In various com-

${ }^{*}$ Corresponding author. munities, the persistence of this disease is mainly due to some prevailing factors such as lack of potable water supply, poverty, ignorance and then poor environmental conditions. The prevalence in many parts of the world is currently increased by modern endeavours to develop and construct water projects to meet local power and agricultural needs $[9,10]$. Schistosomiasis worldwide has brought about one of the greatest public health burdens occurring mainly in developing countries, particularly in sub-Saharan Africa.

Prevalence of Schistosoma infections has increased in Ghana considerably over the past few decades, despite numerous programmes and measures put in place to control the disease. Investigations carried out to determine 
the burden of schistosomiasis in Ghana have mainly been around the Volta Lake [11-13]. The Schistosomiasis Control Programme of the Ghana Health Service (GHS) has mapped out areas showing the prevalence rate within the various regions (Figure 1).

In spite of the success of this exercise, there are several urban and peri-urban communities that are still under the affliction of this parasitic disease. One of the major problems is how to locate these communities. Various ways of spotting these communities have been adopted by the GHS, including data/information on hospital attendance. The shortfall of this strategy can be lack of actual representation to aid in locating these peri-urban communities due to urban migration of people from endemic areas.

Currently, clinically diagnosed schistosomiasis is treated with praziquantel [15]. Although it is the current drug of choice, its use for control of schistosomiasis has some

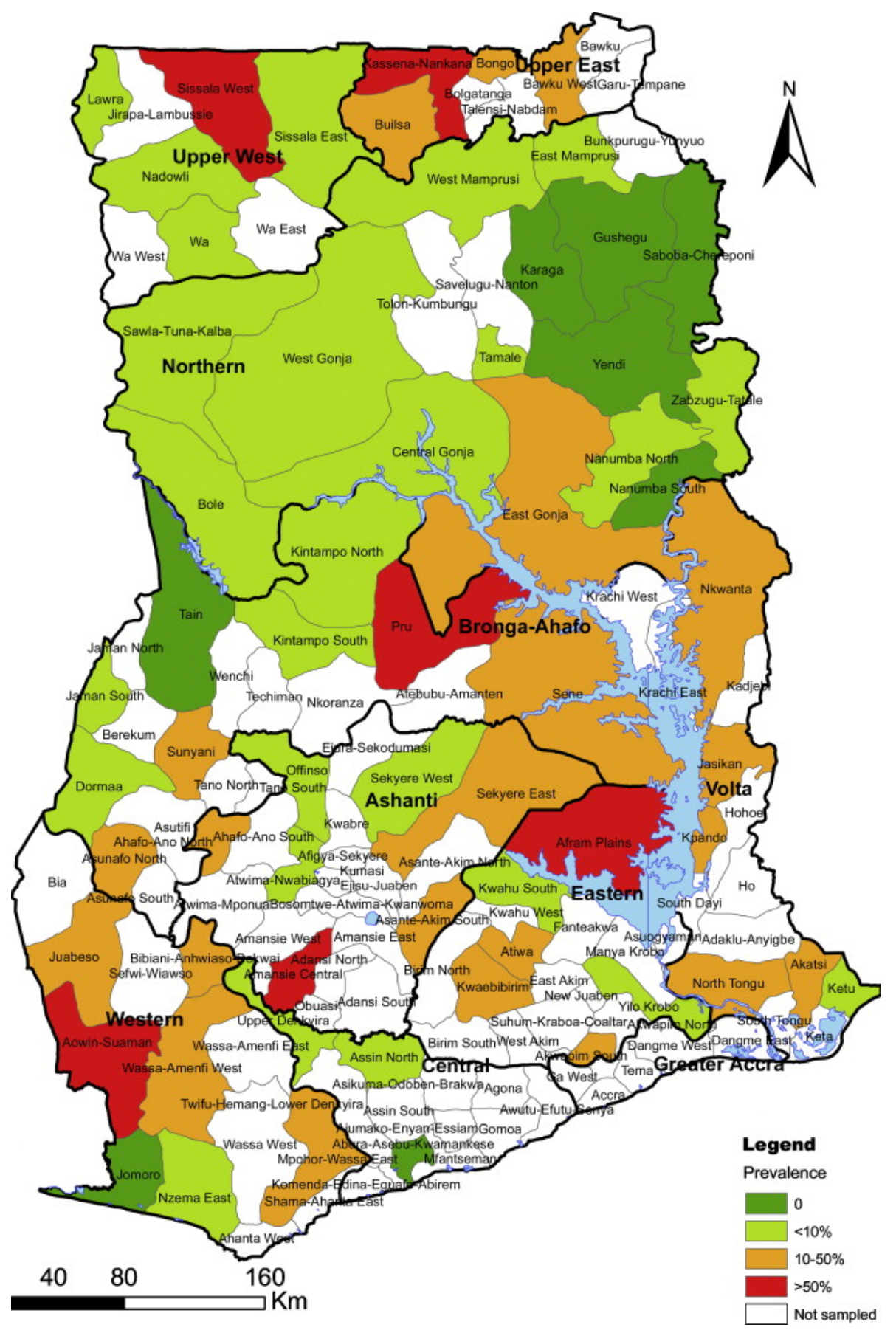

Figure 1. Distribution of Schistosomiasis prevalence across Ghana [14]. 
challenges. Among these challenges are reports of severe and even lethal side-effects in the treatment process, which had to be carefully assessed against the benefits of the patients' early treatment of schistosomiasis and disease prevention $[16,17]$. This observation brings to the fore the need for further investigations to capture information on the prevalence of this infection in neglected areas. Praziquantel is also noted to have little or no effect on the eggs and the immature worms [18]. Another challenge with the control of schistosomiasis using praziquantel is it's unavailability in about $78 \%$ of the health care facilities which are located within schistosomiasis endemic areas [15].

This study therefore, is aimed at determining the urinary schistosomiasis burden among children of school going age within Accra, the capital city of Ghana. The information in this present investigation will update and broaden the picture regarding the prevalence of $S$. haematobium infections in most neglected communities within urban and peri-urban communities in sub-Saharan Africa. Information gathered from this investigation will also go a long way to help in organizing effective schistosomiasis control programmes in afflicted communities.

\section{Materials and Methods}

This was a cross-sectional study conducted in three primary schools in Zenu community (Figure 2), a suburb of Accra. This community is situated in the southern part of Ashaiman (a town on the outskirts of Tema), which forms part of the greater Accra Region of Ghana. Its geographical coordinates are $5^{\circ} 42^{\prime} 0^{\prime \prime}$ North, $0^{\circ} 20^{\prime} 0^{\prime \prime}$ West.

Like the other rural areas within the region, the major economic activities of this community are subsistent farming and fishing with a few inhabitants being civil servants. The presence of a lake in the community might have attracted most of the settlers. The lake serves as a great source of water supply for various domestic activi-

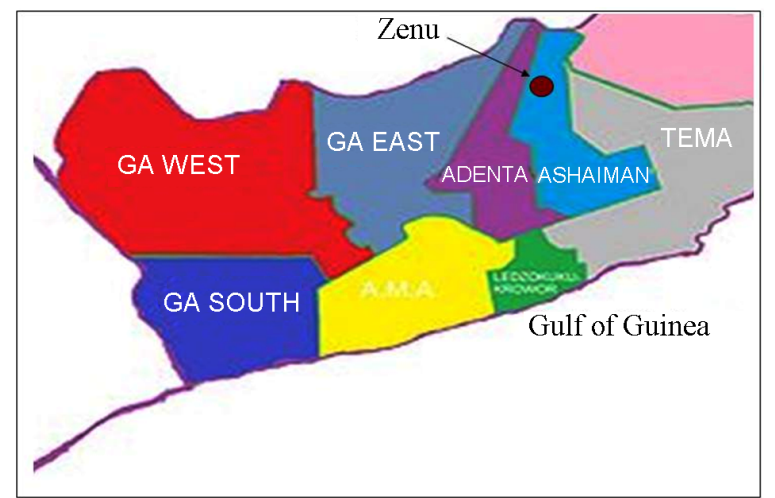

Figure 2. Geographical location of the Zenu community of Ashaiman in the Greater Accra region of Ghana (Adopted and modified from en.wikipedia.org/wiki/Ashaiman Municipal District). ties carried out by the people within the community. This is especially noteworthy since interruption in pipe-borne water occurs frequently in the Greater Accra Region. Some of the residents, majority of which are children also swim in this lake. Since children are most vulnerable and affected by the infection, it became imperative to screen them for the infection. No mass drug administration with praziquantel had been carried out in the Zenu community before the study.

\subsection{Ethical Approval}

The study protocol was approved by the Ethical Review Committee of Department of Science Laboratory Technology, Accra Polytechnic of Ghana.

\subsection{Sample Collection}

Prior to the collection of the samples, verbal interviews and brief discussions were held with the school authorities, children and parents. After obtaining informed consent from parents and teachers, a questionnaire was administered to the parents, teachers and children above 10 years to gather demographic and epidemiologic information, such as age, class, gender, duration of residency in the community, exposure to the water source, distance of house to water source and knowledge on schistosomiasis infection. Urine samples were collected from children attending three private schools within the community.

Clean, dry, leak-proof, and wide-mouthed plastic specimen containers were given to 274 consented subjects randomly from different classes. They were given instructions on how to avoid contamination during collection of the urine samples. Pre-designed questionnaire on their personal data and morbidities such as dysuria and abdominal pain were administered to the children. About $15 \mathrm{ml}$ of terminal urine were collected per child, per school into the specimen containers provided, and the samples were then transported to the Parasitology Laboratory of the Microbiology Department, University of Ghana Medical School and the Department of Medical Laboratory Sciences, School of Allied Health Sciences, Korle-Bu, Accra (Ghana) for analysis.

\subsection{Urine Chemistry Examination}

A volume of $5 \mathrm{ml}$ of thoroughly mixed urine sample was poured into a $10 \mathrm{ml}$ labelled centrifuge tube. Macroscopic examinations were carried out on each sample. Urine chemistry reagent strip (Haemastrix ${ }^{\circledR}$ and Albustrix $^{\circledR}$, AMES Laboratories) were dipped into each urine sample for a few seconds. It was then removed and an approximate time of 60 seconds was allowed to elapse for biochemical reactions of the reagent strip to the urine sample to occur. The outcome of the reaction was compared to a colour chart. The results were recorded with 
emphasis on blood and protein. Any colour change after the stipulated time was ignored [19].

\subsection{Microscopy Examination}

The urine samples were span at $3000 \mathrm{rpm}$ for 3 to $5 \mathrm{~min}$ utes and the deposits examined with the aid of a light binocular microscope using the $\times 10, \times 40$ and $\times 100$ objectives by basic standard protocol [20].

\subsection{Data Analysis}

The data obtained were entered into MS Excel and analyzed using Minitab software version 15 (Minitab Inc. 2010). Prevalence rates were reported in percentages and $95 \%$ confidence intervals. Chi-square $\left(\chi^{2}\right)$ was used to evaluate significant association among the study variables. A P-Value less than 0.05 was considered statistically significant.

\section{Results}

\subsection{Prevalence of Schistosomiasis}

A total of 274 samples were collected from 133 females $(48.5 \%, 133 / 274)$ and 141 males $(51.5 \%, 141 / 274)$. This ratio indicates that, the sample population was almost evenly distributed in terms of gender. The population age ranges from 3 to 16 years (Table 1). Both the mean age and median age were 9.5. 9 years was the age with the highest number sampled with 36 children, followed closely by 12 years with 34 children, then 10 years with 33 children and 11 years with 29 children. Ages 10 and 12 years recorded the highest number of positives with 13 children each (Table 1).

Table 1. Number sampled and number of Schistosoma positives based on age.

\begin{tabular}{cccc}
\hline Age (year) & $\mathrm{N}(\%)$ & $\mathrm{n}(\%)^{\#}$ & $95 \% \mathrm{CI}$ \\
\hline 3 & $5(1.8)$ & $0(0)$ & 0 \\
4 & $6(2.2)$ & $0(0)$ & 0 \\
5 & $27(9.9)$ & $10(3.6)$ & $0-9.6$ \\
6 & $26(9.5)$ & $4(1.5)$ & $0-6.5$ \\
7 & $25(9.1)$ & $7(2.6)$ & $0-8.6$ \\
8 & $28(10.1)$ & $6(2.2)$ & $0-7.2$ \\
9 & $36(13.1)$ & $12(4.3)$ & $0-10.7$ \\
10 & $33(12.0)$ & $13(4.7)$ & $0-12.0$ \\
11 & $29(10.5)$ & $9(3.3)$ & $0-9.8$ \\
12 & $34(12.4)$ & $13(4.7)$ & $0-11.8$ \\
13 & $16(5.6)$ & $6(2.2)$ & $0-9.5$ \\
14 & $4(1.6)$ & $1(0.4)$ & $0-6.8$ \\
15 & $4(1.5)$ & $3(1.1)$ & $0-11.3$ \\
16 & $1(0.7)$ & $0(0)$ & 0 \\
Total & $274(100)$ & $84(30.7)$ & $25.2-36.2$ \\
\hline
\end{tabular}

$\mathrm{n}$ indicates number of children who had schistosomiasis; $\mathrm{N}$ indicates total number of children sampled in a particular age group; \% indicates prevalence of schistosomiasis infection.

$$
{ }^{\#}(\%)=\beta / \alpha \times \infty
$$

$\beta=$ Number of positives

$\alpha=$ Total of number of positives

$\infty=$ Total percentage positive (prevalence rate)

Generally, lower numbers of children were sampled within ages 3 - 4 and 14 - 16 years, as compared to children among ages 8 - 12 years. After analysis of samples, ova of Schistosoma haematobium were found microscopically to be present in 84 out of the total samples from the population (Table 1), representing a prevalence of $30.7 \%(84 / 274,95 \%$ CI: 25.2 - 36.2). Among the positive samples, $44(52 \%)$ belonged to males whiles 40 (48\%) belonged to females. The male to female ratio was 1.1:1. There was no significant difference in prevalence by gender $\left(\chi^{2}=0.041, \mathrm{DF}=1, \mathrm{P}-\right.$ Value $\left.=0.839\right)$.

\subsection{Urine Biochemistry Analysis}

From the examination, blood was detected in the urine of 94 (34.3\%, 95\% CI: 28.7\% - 39.9\%) children (45 females and 49 males) whiles $95(30.6 \%, 95 \%$ CI: $29.0 \%-40.2 \%)$ of them (males 57 and females 38) presented with protein in their urine with varied intensity for both haematuria and proteinuria.

As said in the prevalence results, Schistosoma ova were detected in $30.7 \%$ (84/274; CI: 25.2 - 36.2) children. Among this children, haematuria was detected by the dipstick in $88.1 \%,(74 / 84,95 \% \mathrm{CI}: 81.2-95.0)$ of them but it was not detected in $11.9 \%(10 / 84,95 \%$ CI: 5.0 18.8). Meanwhile, the dipstick detected haematuria in 7.3\% (20/274, 95\% CI: 4.3\% - 7.3\%) children but microscopy results could not detect the presence of Schistosoma ova in them (Figure 3). All the same, there was

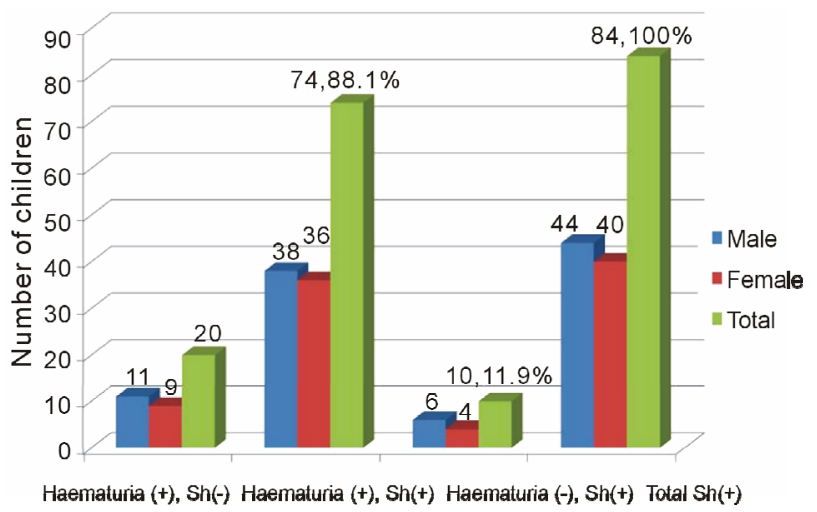

Figure 3. Haeamaturia and its relation to schistosomiasis prevalence among the children. Haematuria(+), $\mathrm{Sh}(-)$ indicates number of children who did not have Schistosoma ova but haematuria was detected; Haematuria(+), $\mathrm{Sh}(+)$ indicates number of children who had Schistosoma ova and haematuria was detected; Haematuria(-), Sh(+) indicates number of children who had Schistosoma ova but haematuria was not detected. 
an association between Schistosoma infection and haematuria detected by dipstick $\left(\chi^{2}=84.715, \mathrm{DF}=1\right.$, P-Value $<0.001)$.

\subsection{Household Proximity and Children Exposure to the Water Source}

Analysis demographic data showed that 17.5\% (48/84, 95\% CI: $10.0 \%-25.0 \%$ ) of schistosomiasis infected children lived closely to the water source (locally called "dam") within a distance of $<1 \mathrm{~km} .5 .1 \%$ (14/84, 95\% CI: $0 \%-10.5 \%$ ) lived within a distance of $1-2 \mathrm{~km}, 4.5 \%$ (12/84, 95\% CI: $0 \%-10.0 \%)$ within a distance of, $2-3$ $\mathrm{km}, 2.2 \%(6 / 84,95 \% \mathrm{CI}: 0 \%-6.5 \%)$ within a distance of, $3 \mathrm{~km}-4 \mathrm{~km}$ and $1.5 \%$ (4/84, 95\% CI: $0 \%-7.2 \%)$, lived within a distance of $>4 \mathrm{~km}$ (Table 2). Household proximity to the water source was found to be associated to prevalence of schistosomiasis $\left(\chi^{2}=25.419\right.$, DF $=4$, P-Value < 0.001) Also, it was noted that, 23.4\% (64/84, 95\% CI: $19.0 \%-28.8 \%$ ) of schistosomiasis infected children visit the "dam" daily. Followed by 5.8\% (64/84, 95\% CI: $0.1 \%-11.6 \%)$ weekly, $1.5 \%$ (16/84, 95\% CI: $0 \%-7.2 \%)$ monthly and $0.4 \%(1 / 84,95 \% \mathrm{CI}: 0 \%-0.9 \%)$ was noted to visit the water source yearly (Table 2). Exposure to the water source was also found to be associated to prevalence of schistosomiasis $\left(\chi^{2}=330.175, \mathrm{DF}=\right.$ 3, P-Value $<0.001$ ).

\section{Discussion}

Even though the sampling was randomly done, the sample population consisted of a fair distribution of females and males. This minimizes any bias that would have been

Table 2. Household proximity and exposure to water source.

\begin{tabular}{ccccc}
\hline $\begin{array}{c}\text { Household proximity to } \\
\text { water source }\end{array}$ & $\mathrm{N}$ & $\mathrm{n}$ & $\%$ & $95 \% \mathrm{CI}$ \\
\hline $\begin{array}{c}\text { P-Value }<0.001 \\
<1 \mathrm{~km}\end{array}$ & 98 & 48 & 17.5 & $10.0-25.0$ \\
$1 \mathrm{~km}-2 \mathrm{~km}$ & 64 & 14 & 5.1 & $0-10.4$ \\
$2 \mathrm{~km}-3 \mathrm{~km}$ & 51 & 12 & 4.4 & $0-10.0$ \\
$3 \mathrm{~km}-4 \mathrm{~km}$ & 44 & 6 & 2.2 & $0-6.5$ \\
$>4 \mathrm{~km}$ & 17 & 4 & 1.5 & $0-7.2$ \\
Total & 274 & 84 & 30.7 & $25.2-36.2$ \\
\hline Exposure to the water & $\mathrm{N}$ & $\mathrm{n}$ & $\%$ & $95 \% \mathrm{CI}$ \\
source & 193 & 64 & 23.4 & $18.0-28.8$ \\
\hline $\begin{array}{c}\text { P-Value }<0.001 \\
\text { Daily }\end{array}$ & 62 & 16 & 5.8 & $0.1-11.6$ \\
Weekly & 17 & 4 & 1.5 & $0-7.2$ \\
Monthly & 2 & 1 & 1 & $0-0.4$ \\
Yearly & 274 & 84 & 30.7 & $25.2-36.2$ \\
Total & & &
\end{tabular}

$\mathrm{n}$ indicates number of children who had schistosomiasis; $\mathrm{N}$ indicates total number of children sampled; \% indicates prevalence of schistosomiasis infection. introduced by a particular gender (male or female). In a study conducted by El Katsha et al. [21] to access the possible effect of gender on schistosomiasis infection in Egypt, a comparable number of females and males were selected for this same reason. In our study, the prevalence rate was found to be $30.7 \%$ of the total sample population. There seems to be no significant difference in the prevalence rates with regards to gender $\left(\chi^{2}=0.041\right.$, $\mathrm{DF}=1, \mathrm{P}$-Value $=0.839$ ). Male to female prevalence ratio recorded was 1.1:1 respectively. This observation could possibly be because children of the same age group, regardless of the gender, mostly involve themselves in similar activities. The general prevalence rate is relatively higher when compared to the results of a study carried out by Koukounari et al. [22] on adults in Northwest villages of Accra, Ghana, where different methods including microscopy were used. In that study a sample size of 220 adults was used with different diagnostic techniques. Even though the microscopy results in the current study appear to be comparable with the ultrasound results (prevalence rate of $31.8 \%$ ) obtained by Koukounari et al. [22], the current results seem to be higher when compared to the microscopy results (with prevalence rate of $15.5 \%$ ) of that study. This suggests that the prevalence rate detected by this study could have possibly been higher, if the microscopy was supported by other methods such as ultrasound, serological anti-IgG or urine antigen detection used by other researchers [22-25]. The results show that, haematuria was detected in $88.1 \%$ (74/84) of the schistosome positive children (Figure 3). There was an association between Schistosoma infection and haematuria detected by dipstick $\left(\chi^{2}=84.715, \mathrm{DF}=1\right.$, P-Value $<0.001)$.

This supports the assertion that haematuria is a good marker for $S$. haematobium infection. In a study conducted by Murare and Taylor, in 1987, they found a correlation between both severity of dipstick proteinuria/ haematuria and intensity of $S$. haematobium infection [19]. In that study although haematuria and proteinuria proved reasonably sensitive indicators of urinary schistosomiasis (78\% and $86 \%$ respectively) and both techniques detected all heavy infections (over 64 eggs $/ 10 \mathrm{ml}$ urine), it was noticed that haematuria had a greater association with urinary schistosomiasis, and helps in drawing more accurate conclusions during diagnosis of proteinuria [19].

The urine biochemistry dipstick did not detect haematuria in $11.9 \%(10 / 84)$ of the schistosome positive children (Figure 3). This could be attributed to the possibility that, the infection might not have reached the stage where there is cumulative inflammation and tissue damage that will lead to detectable haematuria. This reason is based on a general belief that, heavy infection (a high worm burden) places an individual at a higher risk for 
disease formation and presentation of clinical signs. This assertion is conceivable on the basis that, a greater rate of egg deposition in host tissues will result in greater cumulative inflammation and tissue damage, as was shown for haematuria outcomes in the study by Koukounari et al. [22]. The results from children who had Schistosoma ova but had no haematuria based on dipstick detection suggest that diagnosis should not be based on dipstick haematuria detection or visible haematuria alone. Hence microscopy examination and other more sensitive techniques such as antigen detection, molecular methods and ultrasound should be encouraged for a more conclusive diagnosis. Also the fact that the dipstick detected haematuria in $7.3 \%$ of the total population but microscopy results could not detect the presence of Schistosoma ova in them implies that, other methods could have detected the presence of Schistosoma ova. Hence, as said earlier, the prevalence rate could have increased if other more sensitive methods are used. It is therefore suggestive that, detection of Schistosoma haematobium will be enhanced when multiple diagnostic methods are used compared to a single method, as seen in the microscopy outcome of the current study. Schistosomiasis was found more in children whose house are close to the water source $\left(\chi^{2}=\right.$ $25.419, \mathrm{DF}=4$, P-Value $<0.001)$. This means that children may engage in water contact recreational activities close to their homes when not in school. This association is conceivable since these children are also likely to be those who visit the "dam" more frequently $\left(\chi^{2}=330.175\right.$, $\mathrm{DF}=3$, P-Value $<0.001)$. In a similar study, household proximity from open water source was found as a factor associated with urinary schistosomiasis [26].

The difference in the prevalence rate between this study and the Koukounari study could be as a result of epidemiological factors such as the age structure and the occupation of the study population [22]. In the previous study the survey was carried out among all people living in the community whiles the current study focused on active school children [22]. The slight difference could also have arisen from environmental differences, as demonstrated by Patz et al. [27]. The study conducted by Koukounari et al. [22] focused on some Northwest villages of Accra whiles the current study focused on a community in South-Western part of Accra. Therefore, the prevalence difference may be due to the level of endemity in these two areas.

The mean age of the children who participated in the study was 9.5 years (range $3-16$ years). The lower numbers of children sampled within ages $3-4$ and 14 16 years, as compared to those within ages $9-12$ years was due to the fact that the study was limited to basic schools. These basic schools are usually attended by children within ages 6 - 15 years. A study conducted by Sackey in 2007 suggested that, there was generally a higher attendance rate in the basic schools compared to secondary and tertiary schools in Ghana [28]. The outcome of the current study suggests that majority of the children attending these basic schools falls within the ages of $9-12$ years. In addition to recording higher numbers of attendance within the age range of $9-12$, the study found no difference in Schistosoma positivity between these individual ages $(9,10,11$ and 12 , Table 1). This suggests that children within this age range may have similar tendency of getting infected. Explanation to this observation could possibly be because children in this age range may have similar behavioural patterns such as involving themselves in activities that bring them into contact with the water source. Children within this group are considered to be mostly playful, adventurous and also they are those mostly sent by their parents to the lake to fetch water for domestic purposes. In a different study, high prevalence rates were found among both young and older children [29]. Therefore our study findings support the earlier finding by Sackey [28], that schistosome infections can be generally common in children of all ages.

It can therefore be suggested that as to whether age will make a difference or not depends on the population sampled (children or adult). This is because whiles there seem to be no difference in positivity found among individual ages in children, it has been observed in some studies that, age makes a difference when children as a group are compared to adults [30,31]. This suggestion agrees with the conclusion drawn by Doehring [30], that, in endemic areas the childhood age group has the highest prevalence and intensity of infection. A study conducted by Nmorsi et al. [31] in Schistosoma haematobium infected rural Nigerians also concluded that children had a higher prevalence of urinary schistosomiasis than their adult counterparts with, prevalence rates of $30(41.1 \%)$ against $13(20.0 \%)$ respectively. In a similar way, a comparison between the prevalence rate of $15.5 \%$, recorded by Koukounari et al. [22] (which focused on adults), and that of the current work (with prevalence rate of $30.7 \%$ which focused on active school going children) suggest that, there may be a significant difference in the prevalence rate between children and adults in a community. This observation is convincing, since children are those who have much contact with the water sources by involving themselves in various activities such as swimming, playing and bathing in the water. Additionally, this also means that compared to adults, children might have little or no knowledge concerning the association of urinary schistosomiasis infection with the source of the water they have contact with.

\section{Conclusion}

In general, the prevalence rate of urinary schistosomiasis 
infection among the study group is fairly high with a prevalence of $30.7 \%$ among active school children. No association was found between gender and urinary schistosomiasis, however, infection is high in children whose houses are close to the water source. There was an association between Schistosoma infection and haematuria detected by dipstick. It is therefore, hoped that more efforts would be put into developing control measures to prevent infection and reinfection of urinary schistosomiasis among children, even in the capital cities of developing countries, mostly in Africa.

\section{Acknowledgements}

There was no funding for this work and no conflicts of interest. PBT-Q was involved with the conception and writing of the initial draft of the manuscript. All other authors provided important input and suggestions for changes to the initial draft. The authors wish to acknowledge all teachers and students of Nadels Academy, Christ Mission School and Nanes School for their cooperation during the sampling process. We also wish to thank all the staff of the Departments of Science Laboratory Technology and Microbiology (UGMS) for their help.

\section{REFERENCES}

[1] C. H. King, "Long-Term Outcomes of School-Based Treatment for Control of Urinary Schistosomiasis: A Review of Experience in Coast Province, Kenya," Memórias do Instituto Oswaldo Cruz, Vol. 101, No. 1, 2006, pp. 299-306. doi:10.1590/S0074-02762006000900047

[2] A. Koukounari, A. F. Gabrielli, S. Touré, E. BosquéOliva, Y. Zhang, B. Sellin, C. A. Donnelly, A. Fenwick and J. P. Webster, "Schistosoma haematobium Infection and Morbidity before and after Large-Scale Administration of Praziquantel in Burkina," Journal of Infectious Diseases, Vol. 196, No. 5, 2007, pp. 659-669. doi:10.1086/520515

[3] N. Midzi, D. Sangweme, S. Zinyowera, M. P. Mapingure, K. C. Brouwer, N. Kumar, F. Mutapi, G. Woelk and T. Mduluza, "Efficacy and Side Effects of Praziquantel Treatment against Schistosoma haematobium Infection among Primary School Children in Zimbabwe," Transactions of the Royal Society of Tropical Medicine and Hygiene, Vol. 102, No. 8, 2008, pp. 759-766. doi:10.1016/i.trstmh.2008.03.010

[4] J. W. Rudge, J. R. Stothard, M. G. Basáñez, A. F. Mgeni, I. S. Khamis, A. N. Khamis and D. Rollinson, "MicroEpidemiology of Urinary Schistosomiasis in Zanzibar: Local Risk Factors Associated with Distribution of Infections among Schoolchildren and Relevance for Control," Acta Tropica, Vol. 105, No. 1, 2008, pp. 45-54. doi:10.1016/j.actatropica.2007.09.006

[5] B. Gryseels, "The Relevance of Schistosomiasis for Public Health," Tropical Medicine and Parasitology, Vol. 40, No. 2, 1989, pp. 134-142.
[6] M. G. Chen and K. E. Mott, "Progress in Assesment of Morbidity Due to Schistosoma haematobium Infection: A Review of Recent Literature," Tropical Disease Bulletin, Vol. 86, No. 4, 1989, pp. R1-R36.

[7] A. W. Cheever, "Schistosomiasis and Neoplasia," Journal of National Cancer Institute, Vol. 61, No. 1, 1978, pp. 13-18.

[8] D. M. Forsyth, D. J. Bradley and J. McMahon, "Death Attributed to Kidney Failure in Communities with Endemic Urinary Schistosomiasis," Lancet, Vol. 2, No. 7670, 1970, pp. 472-473. doi:10.1016/S0140-6736(70)90095-4

[9] L. Chitsulo, D. Engels, A. Montresor and L. Savioli, "The Global Status of Schistosomiasis and Its Control," Acta Tropica, Vol. 77, No. 1, 2000, pp. 41-51. doi:10.1016/S0001-706X(00)00122-4

[10] J. A. Patz, T. K. Graczyk, N. Geller and A. Y. Vittor, "Effects of Environmental Change on Emerging Parasitic Diseases," International Journal for Parasitology, Vol. 30, No, 12, 2000, pp. 1395-1405. doi:10.1016/S0020-7519(00)00141-7

[11] K. Zakhary, "Factors Affecting the Prevalence of Schistosomiasis in the Volta Region of Ghana," McGill Journal of Medicine, Vol. 3, 1997, pp. 93-101.

[12] D. Scott, K. Senker and E. C. England, "Epidemiology of Human Schistosoma haematobium Infection around Volta Lake, Ghana, 1973-75," World Health Organization, Vol. 60, No. 1, 1982, pp. 89-100.

[13] R. Y.-T. Dzidzo, T. Annang, J. Otchere, D. Bentum, D. Edoh, C. Amoah and K. M. Bosompem, "Urinary Schistosomiasis among Adults in the Volta Basin of Ghana: Prevalence, Knowledge and Practices," Journal of Tropical Medicine and Parasitology, Vol. 34, No. 1, 2011, pp. 1-16.

[14] www.sciencedirect.com

[15] M. J. van der Werf, K. M. Bosompem and S. J. de Vlas, "Schistosomiasis Control in Ghana: Case Management and Means for Diagnosis and Treatment within the Health System," Transactions of the Royal Society of Tropical Medicine and Hygiene, Vol. 97, No. 2, 2003, pp. 146152. doi:10.1016/S0035-9203(03)90102-7

[16] P. Jordan, "From Katayama to the Dakhla Oasis: The Beginning of Epidemiology and Control of Bilharzia," Acta Tropica, Vol. 77, No. 1, 2000, pp. 9-40. doi:10.1016/S0001-706X(00)00121-2

[17] G. R. Olds and S. Dasarathy, "Schistosomiasis," Current Treatment Options in Infectious Diseases, Vol. 2, 2000, pp. 88-99.

[18] B. Gryseels, K. Polman, J. Clerinx and L. Kestens, "Human Schistosomiasis," Lancet, Vol. 368, No. 9541, 2006, pp. 1106-1118. doi:10.1016/S0140-6736(06)69440-3

[19] H. M. Murare and P. Taylor, "Haematuria and Proteinuria during Schistosoma haematobium Infection: Relationship to Intensity of Infection and the Value of Chemical Reagent Strips for Pre- And Post-Treatment Diagnosis," Transactions of the Royal Society of Tropical Medicine and Hygiene, Vol. 81, No. 3, 1987, pp. 426-430. doi:10.1016/0035-9203(87)90158-1

[20] M. Cheesbrough, "District Laboratory Practice in Tropi- 
cal Countries," 2nd Edition, Cambridge University Press, Cambridge, 2005. doi:10.1017/CBO9780511581304

[21] S. El Katsha and S. Watts, "Gender, Behavior, and Health: Schistosomiasis Transmission and Control in Rural Egypt," American University in Cairo Press, Cairo, 2002.

[22] A. Koukounari, J. P. Webster, C. A. Donnelly, B. C. Bray, J. Naples, K. Bosompem and C. Shiff, "Sensitivities and Specificities of Diagnostic Tests and Infection Prevalence of Schistosoma haematobium Estimated from Data on Adults in Villages Northwest of Accra, Ghana," American Journal of Tropical Medicine and Hygiene, Vol. 80, No. 3, 2009, pp. 435-441.

[23] H. Feldmeier and G. Poggensee, "Diagnostic Techniques in Schistosomiasis Control: A Review," Acta Tropica, Vol. 52, No. 4, 1993, pp. 205-220. doi:10.1016/0001-706X(93)90009-Z

[24] V. C. Tsang and P. P. Wilkins, "Immunodiagnosis of Schistosomiasis," Immunological Investigations, Vol. 26, No. 1-2, 1997, pp. 175-188. doi:10.3109/08820139709048925

[25] A. Rabello, "Diagnosing Schistosomiasis," Memórias do Instituto Oswaldo Cruz, Vol. 92, No. 5, 1997, pp. 669676. doi:10.1590/S0074-02761997000500021

[26] A. P. Kapito-Tembo, V. Mwapasa, S. R. Meshnick, Y. Samanyika, D. Banda, C. Bowie and S. Radke, "Prevalence Distribution and Risk Factors for Schistosoma he- matobium Infection among School Children in Blantyre, Malawi. PLoS Neglected Tropical Disease, Vol. 3, No. 1, 2009, p. e36. doi:10.1371/journal.pntd.0000361

[27] J. A. Patz, T. K. Graczyk, N. Geller and A. Y. Vittor, "Effects of Environmental Change on Emerging Parasitic Diseases," International Journal for Parasitology, Vol. 30, No. 12, 2000, pp. 1395-1405. doi:10.1016/S0020-7519(00)00141-7

[28] H. A. Sackey, "The Determinants of School Attendance and Attainment in Ghana: A Gender Perspective," African Economic Research Consortium, Vol. 173, 2007.

[29] J. R. Verani, B. Abudho, S. P. Montgomery, P. N. M. Mwinzi, H. L. Shane, S. E. Butler, D. M. S. Karanja and W. E. Secor, "Schistosomiasis among Young Children in Usoma, Kenya" American Journal of Tropical Medicine and Hygiene, Vol. 84, No. 5, 2011, pp. 787-791. doi:10.4269/ajtmh.2011.10-0685

[30] E. Doehring, "Schistosomiasis in Childhood," European Journal of Pediatrics, Vol. 147, No. 1, 1988, pp. 2-9. doi:10.1007/BF00442602

[31] O. P. Nmorsi, N. C. Ukwandu, S. Ogoinja, H. O. Blackie and M. A. Odike, "Urinary Tract Pathology in Schistosoma haematobium Infected Rural Nigerians," Southeast Asian Journal of Tropical Medicine and Public Health, Vol. 38, No. 1, 2007, pp. 32-37. 